\section{Los migrantes latinoamericanos ante el confinamiento obligatorio por covid-19: fenómenos de readaptación a espacios virtuales digitales y de lazos migratorios}

\author{
JAZMIN SILVA MORA ${ }^{1}$ \\ 0000-0003-0885-4361
}

Université de Toulouse II -Jean Jaurès, Francia

\section{EMILIA LARA WALLE² \\ 0000-0003-0479-5472}

Université de Toulouse II -Jean Jaurès, Francia

Institución Santé Publique France (SpF), Francia

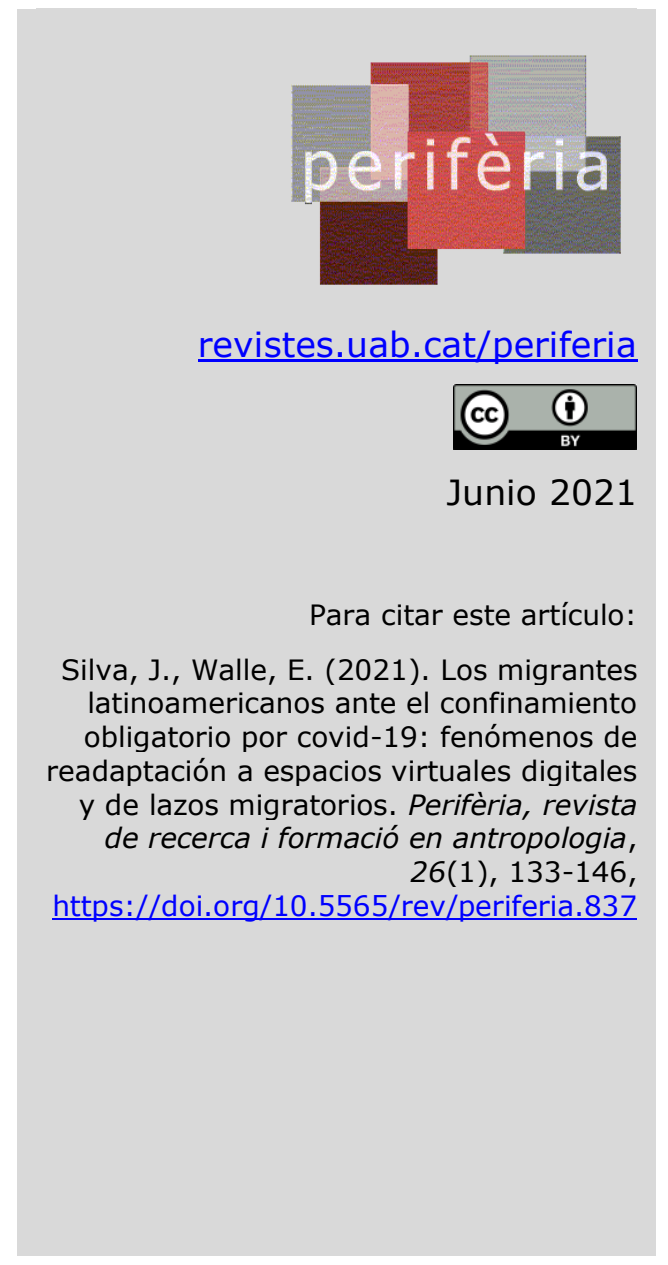

\title{
Resumen
}

El confinamiento por covid-19 desencadenó nuevos hábitos de socialización y comunicación en la población de Toulouse, Francia. Nuestra investigación buscó evidenciar estos nuevos comportamientos a partir de los testimonios de un grupo de 56 migrantes latinoamericanos residentes en esta ciudad. Dichos testimonios fueron recolectados en forma de encuesta virtual Google Forms. Este artículo reúne los resultados del análisis cualitativo y cuantitativo sobre los fenómenos de readaptación a espacios virtuales digitales, así como la importancia de la red migratoria y el circulo social en tiempos de crisis sanitaria.

Palabras clave: Migrantes latinoamericanos; Covid-19; Espacios virtuales; Confinamiento; Toulouse.

\footnotetext{
${ }^{1}$ Contacto: Jazmin Silva Mora - jazmin.silva-mora@etu.univ-tlse2.fr

${ }^{2}$ Contacto: Emilia Lara Walle - larawallee@gmail.com
} 
Abstract: Latin American migrants during covid-19 mandatory social distancing: readjustment to virtual environments, digital spaces and migratory ties phenomena.

The lockdown as a result of Covid-19 brought about new social and communicative habits for the population of Toulouse, France. Our research shows evidence of 56 Latin American migrants' experiences which were collected by a virtual Google Forms questionnaire answered by those living in Toulouse during the official confinement period. This article thus, compiles the results of a qualitative and quantitative analysis of phenomena regarding readjustment to virtual environments and digital spaces as well as the value of migrant networks and social circles during a health crisis.

Keywords: Latin American migrants; Covid-19; Virtual environments; Virtual Spaces; Lockdown; Toulouse.

\section{Introducción}

Vivir en un mundo globalizado es parte de nuestro día a día. Los procesos asociados a la globalización: extensión, aceleración y frecuencia de los intercambios, las comunicaciones y la movilidad, tienen en común el principio de un mundo sin límites, incluso de fronteras desdibujadas (De la Pena Martínez, 2003). A partir de diciembre de 2019, la enfermedad por coronavirus o covid-19 evolucionó rápidamente en pandemia; más allá de la naturaleza contagiosa del virus, la interconectividad, movilidad e interdependencia en el mundo en que vivimos han tenido un rol fundamental en su transmisión a escala mundial.

En el contexto de la globalización actual, los patrones migratorios han aumentado en volumen, diversidad, alcance y complejidad debido a los avances en tecnologías de transporte y comunicación (Czaika y Haas, 2014) a diferencia de aquellos del siglo pasado ligados a un pasado colonial y a corredores migratorios estructurados dentro de la misma área cultural. Esto aumenta la diversidad de los migrantes en países receptores como Francia, lo que nos ayuda a comprender su demografía hoy en día. No obstante, el hecho de que los flujos migratorios y la movilidad han sido facilitados por la globalización, no elimina por completo el estado de vulnerabilidad ni de menor visibilidad de las personas migrantes al enfrentarse a una nueva sociedad. 
Francia confirmó el primer caso de covid-19 en su territorio el 16 de enero del 2020 comenzando con medidas sanitarias regionales para luego decretar la fase 3 de crisis sanitaria, anunciando su primer confinamiento nacional el 16 de marzo del 20203, convirtiéndose así en el cuarto país europeo con más casos de coronavirus: 25.531 decesos al 6 de mayo del 2020 (Jérémie Baruch et al., 2020). Ante esta situación, comenzamos a reflexionar sobre las circunstancias dadas para que un tercio de la población del planeta se confinase y la particularidad que representaba ser migrantes en este contexto. Al entrar en confinamiento, seguimos discutiendo sobre nuestras preocupaciones, la cotidianidad que se transformaba, la situación en nuestros países y cómo esta pandemia cambiaba la relación con la familia y su visión de la crisis sanitaria en Francia, uno de los primeros países que hizo visible la magnitud del virus. De esta manera, como migrantes latinas egresadas de disciplinas en ciencias sociales, este artículo surgió de un cuestionamiento común sobre los cambios en la sociedad, las formas de adaptarse y de afrontar las restricciones ligadas a la crisis sanitaria de un sector de la población del cual formamos parte. Nuestro objetivo consistía en buscar respuestas a la siguiente pregunta; ¿cómo viven la crisis sanitaria y el confinamiento los migrantes latinos de la ciudad de Toulouse?

De acuerdo con cifras del censo de 2016 publicadas por el INSEE (Institut National de la Statistique et des Études Économiques, 2019), Francia cuenta con 249.900 latinoamericanos en su territorio ${ }^{4}$. Estos migrantes se encuentran distribuidos a lo largo del territorio francés, encontrándose el $46 \%$ en la región Parisina mientras que, en la región Occitanie, de la cual la ciudad de Toulouse es la capital, en el 2005 se encontraba el $6,4 \%$ de esta población (Romero, 2016). La ciudad es la cuarta más grande del país, contando con una población de 475.438 habitantes en 2016 (INSEE, 2019).

La presencia de migrantes hispanohablantes en Toulouse está ligada a hechos históricos. En el siglo pasado, los migrantes españoles representaron el 80\% de los

\footnotetext{
${ }^{3}$ Hasta la fecha (abril 2021), Francia ha impuesto tres confinamientos dentro de su política para reducir la propagación del virus: el primero del 17/03 al 11/05/2020, el segundo del 30/10 al 15/12/2020 y un tercero en curso que inició el 26/02/2021 en las regiones más afectadas y luego se expandió a nivel nacional.

${ }^{4}$ Los países latinoamericanos con más migrantes son Colombia (27.500 migrantes) después de Haití y Brasil, seguido por Perú (12.000) y México (11.700).
} 
extranjeros en la región (Teulières y Souchet, 2008) debido a la cercanía de Toulouse con respecto a España, y la llegada de refugiados de la Guerra Civil Española y de trabajadores que llegaron aprovechando la época que Fourastié (1979) llamó los "Treinta Gloriosos" en Francia. El contar con una importante población española ha hecho que Toulouse sea una ciudad atractiva para los inmigrantes latinoamericanos ya que los altos números de hispanohablantes pueden facilitar su adaptación, sin importar el motivo de migración. Además, la Universidad de Toulouse es reconocida por tener una población estudiantil extranjera importante desde mediados del siglo pasado (ibid.) recibiendo en 201916.000 estudiantes extranjeros, un 2\% más alto que la media nacional, donde los países latinoamericanos Brasil, Colombia y México se encuentran entre las 30 nacionalidades más representadas. Cabe destacar que en el marco de esta investigación, el $48 \%$ de los encuestados afirmó haber migrado a la ciudad por motivos académicos, mientras que el $9 \%$ llegó por motivos laborales 5 . Partiendo del hecho de que Francia ha sido una de las mayores áreas de contagio por covid-19 y el rol que Europa tuvo en la expansión del virus; nuestra reflexión se orientó hacia la manera en que la muestra poblacional se adapta a las medidas de confinamiento lejos su país de origen. Esta investigación se construyó en base a las siguientes hipótesis: (1) Las personas migrantes pasan por un nuevo proceso de adaptación a la sociedad francesa en la cual se priorizan los espacios virtuales sobre los físicos, por lo que su manera de comunicarse, rutina de comunicación y uso de las redes sociales se ve afectado; (2) Las personas migrantes logran desenvolverse con mayor facilidad en espacios virtuales digitales y adaptarse a las redes sociales, espacios frecuentados para relacionarse con su país de origen; (3) La red migratoria y el círculo social de los migrantes se fortalece en momentos de crisis, afianzando lazos de cercanía y restableciendo contactos perdidos.

\footnotetext{
${ }^{5}$ Los cuales mostraron interés en retomar sus estudios en esta ciudad.
} 


\section{Metodología}

Nos propusimos realizar una investigación antropológica sobre la vivencia de estar confinado tomando en cuenta la cualidad de migrante. Al enfrentarnos a un contexto nuevo como investigadoras, debimos adaptarnos a un espacio virtual donde se desarrollaron todas las fases del proyecto, incluyendo la realización de las encuestas y el tratado de datos, a través de programas de videoconferencia, documentos compartidos y encuestas en línea. Cabe señalar que esta investigación no es exhaustiva sino un punto de partida para abrir la discusión sobre cómo esta población, que se construye y se desarrolla de manera transnacional, vive la crisis sanitaria en el suroeste francés.

Afín de poner a prueba nuestras hipótesis, se realizó una encuesta en línea de formato Google Forms que compartimos en redes sociales con personas latinoamericanas y en grupos de latinoamericanos de la ciudad de Toulouse. El análisis de la información se hizo con el programa SPSS para procesar los datos cuantitativos. Mientras que para las preguntas cualitativas se procedió a un análisis de contenido, clasificando el mismo en categorías apropiadas.

\section{Covid-19: movilidades limitadas}

Para aprehender el fenómeno del confinamiento por covid-19 sobre las personas migrantes latinoamericanos en Toulouse, algunas teorías de antropología social y sociología de la migración sirvieron de marco para nuestra investigación. Por una parte, teniendo en cuenta el papel de la globalización con respecto a la pandemia, consideramos los enfoques de Augé (2019) sobre la antropología de la movilidad para comprender cómo los movimientos poblacionales (migración, turismo, movilidad laboral, comunicación instantánea, circulación de productos, imágenes e información tienen un papel central en la cotidianidad moderna. Augé (2019) afirma que podemos hacer todo sin necesidad de movernos y sin embargo lo hacemos (ibid.). ¿Es imprescindible moverse hoy en día? ¿Nuestros aparatos electrónicos y tecnologías de información y comunicación (TICs) adquieren un nuevo sentido durante un confinamiento por pandemia viral? El autor acuñó el término de movilidad a domicilio para referirse a estas tecnologías puesto que la computadora y el teléfono celular ocupan el lugar del hogar y son estos aparatos los que a su vez mantienen relación 
permanente con el exterior. Es decir, se vuelven esenciales en situaciones como la actual donde la movilidad física es limitada.

Ahora bien, para poder realizar las actividades cotidianas desde el lugar de residencia a través de las TICs, ocurre sin lugar a duda, un proceso de adaptación para la sociedad en general. Las personas se hallan frente a espacios virtuales que para Guillaume (2000) están compuestos por dos grandes familias de medios que se superponen, se hibridan y hasta en algunos casos, se enfrentan: los medios irradiantes o de difusión ${ }^{6}$ y los nuevos medios, postmodernos y conmutativos ${ }^{7}$. En el caso de las personas migrantes, consideramos que éstos, en su gran mayoría, han utilizado tecnologías dentro de espacios virtuales digitales para realizar su proyecto migratorio así como durante su proceso de adaptación al país destino. Para Czaika \& Haas (2014) la evolución tecnológica ha (1) disminuido los obstáculos financieros para la movilidad, es decir, los costos de viaje y comunicación; (2) fortalecido las redes migratorias y los lazos transnacionales mediante la facilidad de comunicación con familiares y amigos, el envío de remesas y los viajes de ida y vuelta; (3) aumentado la alfabetización digital así como mejorando el acceso a información de carácter "global" e incrementando oportunidades en países anteriormente desconocidos.

En todo caso, los migrantes no están del todo solos, debido a que forman parte de redes sociales por donde pasa, no solamente la información, sino también la solidaridad (Ferrié y Boëtsch, 2014). Al asociar la teoría de red social al entorno urbano, las redes sociales "se pueden definir como grupos de actores delimitados (organizaciones, comunidades, grupos de individuos) que al vincularse forman redes de relaciones donde lo que nos interesa analizar es el proceso de vinculación y las relaciones que se generan en dicho proceso" (Lozares, 1996). Hablamos entonces de estructuras de "redes de redes" (Molina y Ávila, 2010). En antropología de la migración, los procesos de adaptación tienen suma importancia, por ende, el uso que la persona migrante les da a sus redes nos aclara su función de personas-recursos: las redes de las personas migrantes se entrecruzan al momento en que el migrante

\footnotetext{
${ }^{6}$ Libros y periódicos, radio y televisión.

7 Teléfono, computadora y redes, hipertextos e hiper imágenes.
} 
solicita conocimientos que otros tengan en común (ibid.) manifestándose en ayuda mutua.

Al enfrentarnos a un confinamiento obligatorio por urgencia sanitaria, nuestros hábitos de socialización sufren cambios, se produce una socialización virtual cuyas relaciones, aunque sean similares a aquellas de los espacios tradicionales ${ }^{8}$, "es necesario replantear los usos y las relaciones, las identidades y los imaginarios, los textos y los contextos, etc." (Arcila Calderón, 2008, p. 3).

Además, en un mundo globalizado y más aún ante una situación en la cual los límites físicos están bien establecidos, mientras que los espacios virtuales permiten un acercamiento puesto que:

Hace del viajero (migrante, desplazado, exiliado, refugiado, etcétera) una figura cada vez más ordinaria y atractiva, una figura que destrona del escenario antropológico a la figura del lugareño y que sustituye al "nativo" encerrado en los límites de su comunidad, como informante etnográfico ideal" (De la Pena Martínez, 2003, p.179)

Esto permite recopilar testimonios de gran interés.

\section{Resultados y análisis}

La muestra estuvo constituida por 56 personas migrantes procedentes de 13 países latinoamericanos principalmente Colombia (26.8\%), México (32.1\%) y Venezuela $(10.7 \%)^{9}$, con un rango de edad entre 20 a 45 años y diversos motivos de migración.

\footnotetext{
${ }^{8}$ Como la "cooperación, solidaridad, convivencia, conflicto y competencia".

9 El resto de los países representados fueron: Ecuador (7.1\%), Argentina (5.4\%), Costa Rica (3.6\%), Paraguay (1.8\%), Chile (3.6\%), Nicaragua (1.8\%), Perú (1.8\%), Republica Dominicana (3.6\%) y Brasil $(1.8 \%)$.
} 


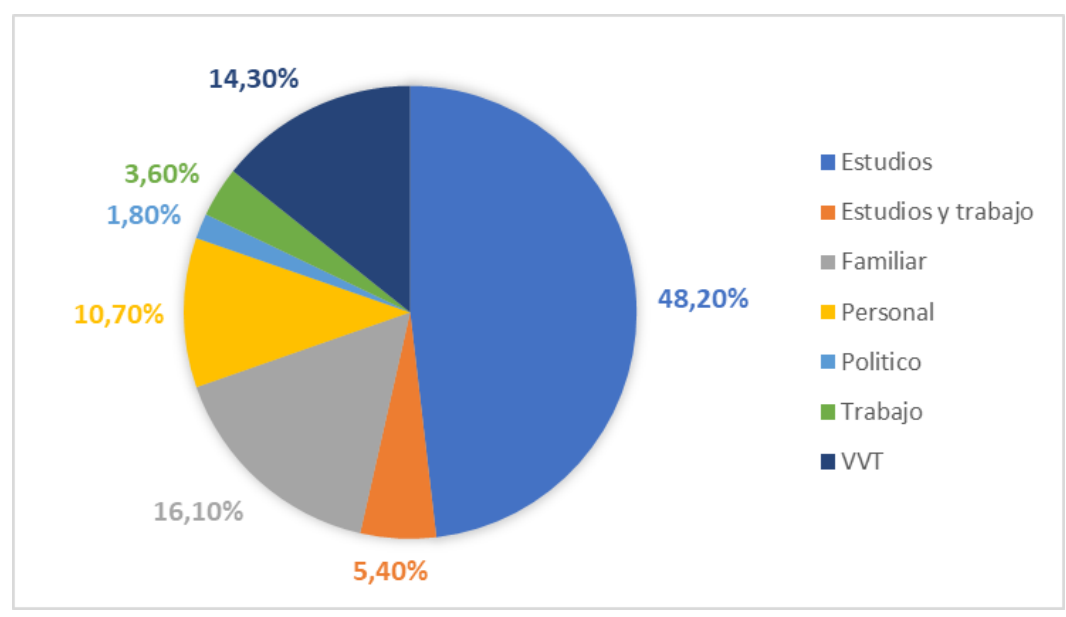

Figura 1: Motivo de la migración a Toulouse. Elaboración propia, 2020

El rango de tiempo viviendo en Toulouse fue de $>1$ año a $<10$ años lo cual nos permitió observar diferentes niveles de adaptación.

El 16 de marzo del 2020 junto con la declaración del inicio del confinamiento, el gobierno promulgó una situación laboral y estudiantil adaptada a la crisis sanitaria trasladando la educación y el trabajo al ámbito virtual.

El $61.4 \%$ de los encuestados se encontraba realizando su actividad principal desde casa: teletrabajo y estudio. Para los migrantes, esto puede representar un quiebre en las relaciones con "colegas de trabajo" y con compañeros de clase, que, en algunos casos, son el único círculo social de la persona migrante. En las encuestas se mencionó una carga de trabajo fuera de lo normal ya que, al estar en casa, las instituciones académicas y empresas dieron por sentado que las personas tenían más tiempo y se encontraban libres para realizar entregas, reuniones en línea y capacitaciones, hecho que antes no se consideraba habitual. Por lo tanto, el confinamiento representó un cambio importante en el contexto laboral y académico. Los encuestados también expresaron que, al no ir al trabajo, no había contacto ni interés de comunicación con colegas, entonces se hace evidente la poca afinidad y relación fuera del espacio laboral. Asimismo, los momentos de ocio ocurren en 
espacios virtuales como es el caso de los apéros ${ }^{10}$, talleres artísticos o sesiones de cocina. Sin embargo, se habla en algunos casos, de una interacción "frustrante" por videollamada, o del hecho que la comunicación se torne difícil cuando el tema principal no deja de ser el coronavirus.

Con el objetivo de conocer los hábitos de los encuestados en espacios virtuales digitales, les pedimos que reflexionaran sobre cómo distribuían su tiempo entre espacios físicos y virtuales durante la cuarentena ${ }^{11}$. A lo cual, $20 \%$ de los encuestados respondió que pasaba la mitad del tiempo en espacios virtuales, mientras que un tercio de ellos pasaba entre $61 \%$ y $80 \%$ de su tiempo en dichos espacios. Si bien el rango de edad de la mayoría de nuestros participantes está entre los 20 y 30 años; generaciones que están en contacto con el mundo digital con mayor facilidad, es interesante notar que hay una relación entre la cantidad de tiempo que llevan en la ciudad de Toulouse y el tiempo que pasan en espacios virtuales: las personas que migraron hace menos de 4 años son aquellas que pasan mayor parte de su tiempo (40-80\%) en espacios virtuales digitales. Además, el tiempo que pasan en espacios virtuales puede estar sujeto al tipo de vivienda donde pasan el confinamiento. Constatamos que aquellas personas que residen en espacios más pequeños como un estudio de $9 \mathrm{~m}^{2}$ en residencia universitaria ${ }^{12}$ suelen dedicarles más tiempo a espacios virtuales digitales.

Los participantes notaron cambios de frecuencia en la comunicación con el país de origen y algunos recurrieron a una modalidad distinta a la habitual, por ejemplo, los mensajes, audios y llamadas fueron reemplazados por las videollamadas. De las 43 personas que indicaron utilizar aplicaciones de mensajería instantánea, 34 afirmaron utilizar la aplicación WhatsApp. Asimismo, de las 28 que manifestaron comunicarse por redes sociales, 12 mostraron preferencia por Facebook. De manera particular, 11

\footnotetext{
10 Tradición francesa del aperitivo que consiste en reunirse para compartir bebidas y charlar.

${ }^{11}$ Por ejemplo: $40 \%$ espacios físicos y $60 \%$ en virtuales.

12 En ocasiones compartido con otra persona, como por ejemplo la pareja.
} 
participantes ${ }^{13}$ complementan el uso de aplicaciones y/o redes sociales accionadas por internet con llamadas telefónicas hacia su país de origen.

Por otra parte, 43 de las personas encuestadas reconocieron que el haber utilizado previa y habitualmente aparatos y tecnologías de comunicación instantánea, para contactar con personas en su país de origen, les ha facilitado la comunicación durante el confinamiento. Igualmente, a raíz de la covid-19, no solamente se generaron cambios en la frecuencia del uso de las aplicaciones y redes sociales que los migrantes ya venían utilizando, sino también confirmamos la incorporación de algunas nuevas para 12 de ellos: Zoom, Skype y Google Meet, entre otras. Este fenómeno lo consideramos como una readaptación al uso de tecnologías que los participantes ya venían utilizando en su condición de migrantes, para comunicarse con sus círculos sociales en el país de origen, ahora utilizadas también para comunicarse con su círculo social y profesional en Toulouse. Como acota Arcila Calderón (2008), "la diferencia entre la socialización [...] en los espacios físicos y aquella que tiene lugar en los entornos virtuales viene dada básicamente por la mediación de las herramientas informáticas que se convierten en la infraestructura de la interacción". Asimismo, en la encuesta buscamos conocer la percepción de los migrantes sobre la situación de crisis sanitaria en Francia y en su país de origen. En el caso de Francia, se habló de incertidumbre por la economía del país, pero también por el hecho de ser extranjero (estatus legal, económico y de salud), además de una fuerte añoranza y preocupación por el país de origen y por la familia que ahí se encuentra. Sobre el país de origen, se habló principalmente de una preocupación por la manera de enfrentar el virus y las consecuencias sanitarias, económicas y sociales que habrá después de la pandemia. También observamos, muestras de añoranza y nostalgia para con la familia y el país de origen.

Estas realidades pueden estar ligadas al interés de los encuestados por fortalecer redes de solidaridad entre migrantes, las cuales sirvieron para mantenerse informados sobre la evolución de la crisis sanitaria, y en las que se desarrolló la ayuda mutua: 35 personas afirmaron que la relación con otros migrantes en Toulouse había cambiado y en la mayoría de los casos se reforzó. Surge constantemente la idea de

\footnotetext{
${ }^{13}$ En su mayoría de nacionalidad venezolana, lo que podría estar ligado a las interrupciones constantes de servicio eléctrico y de internet producto de la fuerte crisis que sobrelleva dicho país.
} 
"estar al pendiente" (estado físico y emocional) del círculo social migrante, especialmente de aquellos que viven solos. Debido al estado de incertidumbre que generó el confinamiento para la sociedad en general, y aún más para las personas migrantes al existir una preocupación dividida entre su círculo social en el país receptor $y$ aquel en el país de origen, el apoyo entre migrantes juega un rol fundamental para enfrentar esta crisis sin precedentes.

\section{Conclusiones}

Esta investigación tiene la singularidad de que se realizó durante dos meses de confinamiento, en los cuales nosotras como investigadoras nos encontrábamos, al igual que los encuestados, en condiciones limitadas: por una parte, al reflexionar, hacer un trabajo de campo, análisis e intercambios en espacios virtuales digitales, y por otra al ser migrantes latinoamericanas con nuestras propias vivencias que debimos apartar siguiendo la rigurosidad científica. Consideramos que encuestar a otros migrantes nos permitió aprehender el fenómeno desde un ángulo general y a su vez, a través de sus múltiples subjetividades. Más allá de las líneas generales de nuestro trabajo, pudimos también constatar reacciones en los migrantes a un posible contagio y un rol asumido de testigos de la expansión del virus en Europa y simultáneamente de informantes hacia su país de origen.

La covid-19 generó grandes cambios en los modos de socialización de la población francesa y de los migrantes latinoamericanos, quienes además adaptaron sus hábitos de comunicación en espacios virtuales digitales. Mediante esta investigación buscamos comprender la experiencia de las personas migrantes latinoamericanas en Toulouse específicamente en cuanto a la readaptación a los espacios virtuales anteriormente utilizados, la facilidad del desenvolvimiento en dichos espacios y el fortalecimiento de la red migratoria. Confirmamos que las personas migrantes de la ciudad de Toulouse lograron readaptarse a las nuevas formas de socialización virtual debido a su conocimiento y uso previo de las redes sociales. Sin embargo, se priorizó la comunicación con el país de origen, así como entre la red migrante latinoamericana la cual se fortaleció. Las respuestas de las personas migrantes encuestadas nos llevaron a reflexionar sobre el estado de sus lazos con amigos y colegas franceses, ya que observamos que dichos círculos sociales fueron poco mencionados. 
Si bien esta investigación nos permitió confirmar nuestras hipótesis, las respuestas obtenidas en el cuestionario sirvieron para visibilizar temas de interés que pudieran ser objeto de investigaciones subsecuentes enfocadas a múltiples disciplinas como por ejemplo: la etnografía multisituada, al considerar otras ciudades de Francia ya sea en base a su población latina y/o su clasificación como zona de alerta roja por covid-19; la antropología transnacionalista, donde se tome en cuenta la experiencia de miembros del círculo social de la persona migrante en su país de origen; la sociología de género para profundizar sobre las redes de ayuda mutua y hacer frente a la vulnerabilidad de mujeres latinoamericanas durante el confinamiento; y finalmente, desde una mirada interdisciplinaria, el fenómeno de la respuesta de migrantes provenientes de culturas colectivas como las latinoamericanas para con sus pares que viven solos y que pasaron la cuarentena de esta manera.

\section{Bibliografía}

Arcila Calderón, C. (2008). La identidad como mediadora de la comunicación en los entornos virtuales | Telos. Telos: Cuadernos de comunicación e innovación, 77. https://doi.org/10.3989/isegoria.2008.i38.411

Augé, M. Anthropologie de la mobilité. (2019, septiembre 27). [Video]. https://videos.uni-koeln.de/de/video/index/file_id/2942

Baruch, J. et al. (2020). Coronavirus : Visualisez l'évolution de l'épidémie en France et dans le monde. Le Monde.fr. https://www.lemonde.fr/lesdecodeurs/article/2020/05/05/coronavirus-age-mortalite-departements-payssuivez-I-evolution-de-I-epidemie-en-cartes-etgraphiques_6038751_4355770.html

Czaika, M., y Haas, H. (2014). The Globalization of Migration: Has the World Become More Migratory? International Migration Review, 48(2), 283-323. https://doi.org/10.1111/imre.12095

De la Pena Martínez, F. (2003). Antropología del presente y globalización. Boletín de Antropología Americana, 39, 175-183. JSTOR. https://www.jstor.org/stable/40978226 
Ferrié, J.-N., y Boëtsch, G. (2014). L'immigration comme domaine de l'anthropologie. En Ferrié, J.-N., y Boëtsch, G. (2014), Anthropologie de l'immigration (pp. 717). Institut de recherches et d'études sur les mondes arabes et musulmans. http://books.openedition.org/iremam/2726

Fourastié, J. (1979). Les trente glorieuses: Ou la révolution invisible de 1946 à 1975. Fayard.

Guillaume, M. (2000). La maîtrise virtuelle de l'espace réel. Réseaux. Communication - Technologie - Société, 18(100), 59-79. https://doi.org/10.3406/reso.2000.2212

Lafon, C. (2020). Coronavirus: Les grandes dates de l'épidémie du Covid-19 en France et dans le monde. Sud Ouest. https://www.sudouest.fr/2020/04/02/coronavirus-les-grandes-dates-de-Iepidemie-dans-le-monde-73823315022.php?fbclid=IWAR3AftXK35n6dnUavOC4TWE3bQ5g_y6R9GLoDQmpcKcwG Ss64f_8lj-KrHo

Lozares, C. (1996). La teoría de redes sociales. Papers. Revista de Sociologia, 48(0), 103-126. https://doi.org/10.5565/rev/papers/v48n0.1814

Molina, J. L., y Ávila, J. (Eds.). (2010). Antropología y Redes Sociales. Una introducción a UCINET6-NETDRAW, EGONET y el análisis comparado con SPSS. Universidad Federico Villarreal. http://revistaredes.rediris.es/recerca/Egoredes/antropologia_y_redes_sociales.pdf

Teulières, L., y Souchet, F. (2008). Histoire des immigrations en région MidiPyrénées. Hommes \& Migrations, 1273(1), 152-166. https://doi.org/10.3406/homig.2008.4738

\section{Webgrafía}

INSEE. (2019). Villes et communes de France - Tableaux de l'économie française | Insee. https://www.insee.fr/fr/statistiques/3676570?sommaire $=3696937 \& \mathrm{fbclid}=$ IwA R3DgatDQvNyZlzGI9rHnKXuBnI7DN6InrCIGilOMnAPKvx3keqd9r3obd4 
INSEE. (2019). Immigrés par pays de naissance détaillé - Étrangers - Immigrés: Pays de naissance et nationalités détaillés | Insee. https://www.insee.fr/fr/statistiques/4197231?sommaire $=4197305 \& q=$ repartiti on+d\%27immigr\%C3\%A9s+par+pays+de+naissance

Romero, J. A. (2016). Défis et apports des récits de vie et de l'ethnographie multisituée dans l'étude de populations migrantes minoritaires: Le cas des Latinoaméricains en France. 14. https://hal.archives-ouvertes.fr/hal-01314915 